\title{
Closed Globe Injury
}

National Cancer Institute

\section{Source}

National Cancer Institute. Closed Globe Injury. NCI Thesaurus. Code C118747.

Traumatic injury to one or more intraocular structures without full thickness wound of the eyewall (sclera and cornea). (adapted from the Birmingham Eye Trauma

Terminology System (BETTS)) 